\title{
Formation of Professional Competence of Students of Technical Universities through Interdisciplinary Integration
}

\author{
Khimmataliev Dustnazar Omonovich, Khakimova Muhabbat Fayzievna, Abdullaeva Ranazhan \\ Matyakubovna, Beknazarova Zamira Farmanovna, Minlishev Rafik Zilievich
}

\begin{abstract}
The article is devoted to one of the most pressing challenges facing higher education today - the formation of professional competence of university students. The competitiveness of the labor market demands of today's students meet modern requirements of economic development, and subsequently formed the competence ensure readiness of students for their professional activities. Therefore, the authors believe that the professional competence of students of technical colleges can begin to form in the first stage of training through the context of learning and interdisciplinary integration, since contextual training constructed professional skills of students to carry out engineering activities, including many aspects, and interdisciplinary communication, in turn, It combines their knowledge and skills from different disciplines, directs the final result - the professional competence. Formed quality will help future technicians holistically apply knowledge of different fields of science in their professional engineering and be competitive specialists in the conditions of modernization of modern enterprises.
\end{abstract}

Keywords: competence, interdisciplinary integration, binary lecture, professional activity, education, graduate.

\section{INTRODUCTION}

In modern society, the level of development of a country depends not only on its technical capabilities, but also on the professional competence of specialists in higher education.

According to N. Muslimov and K. Abdullaeva, competence is the degree of independent and creative application of a combination of theoretical knowledge, skills and abilities acquired in practice, which also forms student practice and postgraduate activity [4].

The modern labor market, with growing demands on the quality of education today, will increase the competence and professional training of future specialists, which, in turn, will increase competition among graduates of higher educational institutions, including technical universities.

\section{Revised Manuscript Received on November 17, 2019}

* Correspondence Author

Khimmataliev Dustnazar Omonovich, Doctor of Science in Education, Acting Professor Tashkent Institute of Irrigation Engineers and agricultural mechanization, Uzbekistan.

Khakimova Muhabbat Fayzievna, Doctor of Science in Education, Professor, Tashkent State University of Economics, Uzbekistan.

Abdullaeva Ranazhan Matyakubovna, Candidate of Psychological Sciences, Associate Professor, Tashkent State University of Economics, Uzbekistan. Beknazarova Zamira Farmanovna, Senior Lecturer, Tashkent Institute of Irrigation Engineers and agricultural mechanization, Uzbekistan.

Minlishev Rafik Zilievich, Head of Department, Applicant Tashkent Institute of Irrigation Engineers and agricultural mechanization, Uzbekistan.

\section{MATERIAL AND METHODS}

If the initial qualification of a specialist is related only to the workplace and the acquisition of narrow information, student training is focused on standard knowledge, skills and competencies, and "competency" primarily differs, which involves the acquisition of knowledge not only in general. but also in the field. training and the ability to successfully implement their skills, increase the efficiency and quality of their activities.

The implementation of such ideas consists in the comprehensive training, formation and development of modern people as specialists, professional competencies and members of society and the community, based solely on a competent approach to professional competence and education.

Most researchers (A.V. Khutorsky and others) recognize competency as mastering the skills necessary for effective professional activity in accordance with pre-established training requirements [1].

\section{RESULTS AND DISCUSSION}

Competence can be defined as a set of personal qualities of a student, designed to prepare for a variety of professional activities.

Following the ideas of A.V. Khutorsky, E.V. Perekhozheva, N. A. Muslimov and other researchers, those who work in this field can then apply their knowledge of engineering higher education as a union of personal qualities for students of technical universities. and help them successfully realize their skills and abilities.

In turn, a competent approach will require significant changes in educational technology. Therefore, today, higher education institutions are faced with the task of developing special technologies and methods for their implementation in the educational process. Unfortunately, the essence of interdisciplinary competence is not fully disclosed in higher educational institutions of the country, because there are no approaches to the theory and methodology of professional education, and there is little potential for natural implementation, as well as technologies aimed at building professional competence of students' skills.

But we believe that, like many researchers, those who work in this area, future specialists of technical universities, have yet to develop meaningful educational and interdisciplinary ties to build professional competence. Since meaningful 
education takes place, modeling of professional and social aspects of future engineering activities, and interdisciplinary integration, in turn, acts as a unifying element in various fields of science. In addition, now it can become the basis of theoretical knowledge aimed at supplementing the total volume of innovative technologies, and his scientific achievements testify to the need for research activities.

A modern graduate - a future technical specialist (professional) - must be able to apply a set of knowledge in various disciplines in his professional activity [5].

The concept of "interdisciplinary integration" in scientific and pedagogical literature is vague, which emphasizes its various roles and roles among pedagogical categories.

According to E.B.Shoshtaeva, interdisciplinary communication is a process of learning disciplines, reflecting a unit of professional activity, continuous and holistic phenomena [2].

E.V. Perekhozheva defines interdisciplinary integration as the process of integration of academic disciplines based on light knowledge and technological problems [3].

For us, interdisciplinary integration is a set of goals, principles and values of training in creating a comprehensive interaction of all academic disciplines. Therefore, at the first stage of students' training, professional competence begins to develop so that high school students quickly make optimal decisions in any complex professional situation in which they can develop independent activity skills through interdisciplinary communication.

Initially, student teams can be formed to educate students in various fields to work together on academic and research tasks. They not only master the nature of their professional activities, they also develop communication skills, communication skills in society. This can be achieved through a series of coursework and research activities.

The task of the research and teaching staff is to direct students to independent and creative work, find solutions to a particular problem and realize their ideas through discussion from a personal point of view.

Students can work together on a task to formulate a model for implementing innovative projects. In addition, future teachers may plan to defend the final student enrollment in their work programs, where student teams present interdisciplinary projects. In preparation, each student solves his own narrow task, and all team members understand how to transfer and coordinate their results, which are necessary to complete common tasks.

To achieve the goals and objectives of professional competence of students through interdisciplinary integration, teachers of higher educational institutions should systematically carry out this work. For this purpose, the curriculum should include binary and integrated lectures, plans for the delivery of lecture material from different departments, different disciplines and cycles, and, therefore, to build bridges in different disciplines.

For example, "Hydrotechnical development of agriculture", "Hydraulics", "Hydrotechnical facilities", etc. It combines science and uses active and interactive teaching methods, such as clusters, media education, basics, discussions, etc. The organization of such classes will help students not only conduct technical courses in the humanities, but also find their relationship and a more rational and informed approach to work in the future [5].

Practice with students can also be organized using interdisciplinary communication. For example, combining the disciplines of hydraulic engineering and water management, students not only look at canals and their rehabilitation measures, but also try to calculate their economic efficiency. For example, they can combine (combine: interdisciplinary, interdisciplinary, joint lessons) in the study of "Resistance of materials", "Physics" and "Chemistry" and offer students tasks related to the search for the structure and properties of the material.

Using information and communication technologies in multidisciplinary laboratories, they can also find application in the educational process, for example, in theoretical mechanics and in the field of "educational technologies", by identifying tasks in this area and developing innovative discoveries. Joint interdisciplinary seminars on the subject of "Physics", "Mathematics" and "History" allow students to consider the historical problems of the development of science, their biographies of prominent scientists, their impact on socio-economic development.

Therefore, the ability to apply knowledge from different disciplines, transfer ideas and ideas from one subject to another is the key to preparing students for future professional activities.

The only multidisciplinary approach is the difficulty of determining student knowledge assessments between the humanitarian, general and special disciplines of the cycle. That is, the level of knowledge of students may not be sufficient to study humanitarian and general faculties. Thus, this knowledge is necessary for teachers not only to develop a cycle of curricula for content development, but also to assess knowledge and skills. Throughout the entire educational process, professional competence through observation was formed and applied at various stages of acquiring sufficient knowledge.

Interdisciplinary integration will lead to the best results if general educational technologies are used in teaching various disciplines of the cycle. Active and interactive teaching methods, including the use of complex computer programs and specialized laboratory equipment, are important for technical universities. Each year, new technical disciplines appear in the learning process at technical universities. This is not surprising, since the rapidly developing industry and economy must change people's minds and make new discoveries for humanity.

When such special disciplines are necessary, for example, in the field of higher education, measures "Water Management and Land Reclamation" will be taken to improve land reclamation, innovative technologies to develop effective inventions in the field of irrigation and land reclamation, and others. It is more difficult to find interdisciplinary connections with the science of cycles, so the expert assessment method can help build a diagram between disciplines.

In the intermediate stages, teachers act as experts, lecturing using interdisciplinary communications, and endpoints can be independently reviewed by independent teachers or online. 
It should also be noted that students should be able to diagnose their knowledge, participate in interdisciplinary activities, and this should be done regularly at intermediate stages - where control points and knowledge testing are planned.

Thus, professional activities and interdisciplinary integration are justified by the fact that only technical practice can improve the knowledge gained in the study of theoretical material if university students perform integration tasks with regular use. The student receives the necessary practical skills for successful professional activities in solving laboratory problems. Graduates can master professional skills, have the opportunity to successfully compete in the labor market, creatively use their professional skills and achieve the highest quantitative and qualitative indicators.

Interdisciplinary communication in educational (training programs) programs may not be the only goal, but a holistic approach is needed, thanks to which the interdisciplinary idea is realized in the learning process. Representatives of the pedagogical sciences believe that interdisciplinary integration into the educational process can be achieved through the use of the above-mentioned active and interactive pedagogical methods, techniques and organizational forms of training.

\section{CONCLUSIONS}

Interdisciplinary integration of students in higher educational institutions plays an important role in improving the quality of scientific, theoretical and practical training of students, since the implementation of interdisciplinary approaches affects not only education (the curriculum), but also the development and development of modern students. , Through the prism of professional competence, the foundation is laid, for all graduates require complex solutions to problems that arise in real life. A comprehensive (universal), creative, emerging professional (professional) personality can be formed only in the context of an inextricable pedagogical process with the professional competence of an engineer based on the general principles and methods of each step. That is why interdisciplinary integration is a prerequisite for the training and education of students of technical universities.

\section{REFERENCES}

[1]. Khutorskoy A.V. Key competencies as a component of a personality-oriented education paradigm / A.V. Khutorskoy // Public Education. 2003. No. 2. P. 55-61.

[2]. Shoshtaeva E.B. Integrated learning technology as a basis for improving the quality of the educational process: author. dis. Cand. ped sciences / E.B. Shoshtaeva. Karachaevsk, 2003.23 s.

[3]. Perekhozheva EV Formation of professional competence of students of technical universities on the basis of interdisciplinary integration: author. dis. Cand. ped sciences / E.V. Perekhozheva. Chita, 2012.23 s.

[4]. Muslimov NA, Abdullaeva Q. Some issues of developing the professional competence of future vocational college teachers. / Materials of the Republican scientific-practical conference "Theory and practice of professional development of pedagogical and administrative personnel of higher education institutions". Tashkent: TSPU, 2012 - pp. 26-28.

[5]. Khimmataliev D.O. Integration of pedagogical and technical knowledge in diagnostics of preparation for professional activities. Monograph. —Tashkent, "Teacher", 2018. - 168 p. 